\title{
KEANEKARAGAMAN SPESIES ULAR DI DESA PERING, KECAMATAN BLAHBATUH, KABUPATEN GIANYAR, BALI
}

\author{
SNAKE DIVERSITY IN PERING VILLAGE, BLAHBATUH, \\ GIANYAR REGENCY, BALI
}

\author{
I Gede Made Arius Hady Budiada, I Gede Agus Pradana Putra, dan \\ IDA BAGUS MADE SUASKARA \\ Prodi Biologi, Fakultas Matematika dan Ilmu Pengetahuan Alam, \\ Universitas Udayana, Kampus Bukit Jimbaran \\ Ariusjhonny@gmail.com
}

Naskah diterima 26 Mei 2016, Naskah disetujui 27 Februari 2017

\section{INTISARI}

Ular merupakan reptilia berdarah dingin yang termasuk dalam ordo Squamata dan subordo Serpentes. Ular banyak dijumpai di dataran rendah, dataran tinggi, baik di pohon, di dalam tanah, air maupun rawa-rawa. Masyarakat di Desa Pering tepatnya Banjar Perang Sada memiliki pengetahuan yang rendah mengenai spesies ular yang berbisa dan spesies ular yang tidak berbisa, sehingga perlu dilakukan penelitian untuk mengetahui keanekaragaman spesies ular di Desa Pering, Kecamatan Blahbatuh, Kabupaten Gianyar. Penelitian ini dilaksanakan pada tanggal 28 Januari - 4 Februari 2015. Pengambilan data dilakukan dengan metode jelajah dengan cara menentukan habitat yang kemungkinan sesuai untuk ular. Pengambilan data dilakukan pada malam hari pukul 19:00-23:00 WITA, pengambilan sampel difokuskan di Banjar Perang Sada pada dua plot/tempat yang berbeda dari habitat sama yaitu persawahan yang ada di dekat pemukiman warga dan persawahan yang ada di dekat Pura Beji. Ular yang ditemukan dicatat dan diidentifikasi secara in situ. Penelitian ini menmukan yang sembilan spesies yaitu, Ahaetulla prasina, Boiga cynodon, Dendrelaphis pictus, Pareas carinatus, Ptyas korros, Rhabdophis chrysargos, Xenochrophis piscator, Bungarus fasciatus, dan Trimeresurus insularis dan spesies dengan jumlah terbanyak adalah Dendrelaphis pictus.

Kata kunci : Ular, Keanekaragaman, Colubridae, Elapidae, Viperidae

\begin{abstract}
Snakes are cold-blooded reptiles belong to the Order Squamata, Suborder Serpentes. Snakes often found in lowlands, highlands, trees, soil, water and swamps. People in the Pering village especially in Banjar Perang Sada have less knowledge about venomous and non-venomous snakes. Therefore, it is important to investigate the diversity of snakes in the Pering village, Blahbatuh, Gianyar. This study was conducted on 28 January -4 February 2015. Data collection was performed by direct observation along the potential snake habitats in two plots rice field near residential area and near the Pura Beji. Data collection was performed during night time from at 7:00 to 11:00 PM with sampling focused on Banjar Perang Sada. Individual snake found was cought and identified in situ. This research found 9 species of snakes namely, Ahaetulla prasina, Boiga cynodon, Dendrelaphis pictus, Pareas carinatus, Ptyas korros, Rhabdophis chrysargos, Xenochrophis piscator, Bungarus fasciatus, and Trimeresurus insularis, the most commonly found was Dendrelaphis pictus.
\end{abstract}

Keywords : Biodiversity, Colubridae, Elapidae, Snake, Viperidae

\section{PENDAHULUAN}

Ular merupakan reptilia berdarah dingin yang termasuk dalam ordo Squamata dan subordo Serpentes. Ular banyak dijumpai di dataran rendah, dataran tinggi, baik di pohon, di dalam tanah, air maupun rawa-rawa (Herbert et al, 2012).

Keanekaragaman spesies ular di Indonesia tercatat sebanyak 109 spesies ular di pulau Jawa (De Rooij, 1917). Hasil beberapa penelitian pada tahun-tahun setelahnya hanya ditemukan 49 spesies di Jawa Timur oleh Hodges (1993), 21 spesies di Taman Nasional Gunung Halimun (TNGH) Jawa Barat Sidik (1998), kemudian penelitian ulangan dilakukan kembali di Taman Nasional Gunung Halimun (TNGH) oleh Mumpuni (2001) dan ditemukan 42 spesies reptil. Di Jawa Tengah, berdasarkan pene- 
Tabel 1. Spesies dan persentase keberadaan ular di Desa Pering, Kecamatan Blahbatuh, Kabupaten Gianyar

\begin{tabular}{|c|c|c|c|c|}
\hline No & Famili & Nama lokal & Nama latin & Jumlah Ular (\%) \\
\hline \multirow[t]{7}{*}{1} & Colubridae & Ular pucuk & Ahaetulla prasina & 33,28 \\
\hline & & Ular kucing bergigi panjang & Boiga cynodon & 1,28 \\
\hline & & Ular tali/ular jali & Dendrelaphis pictus & 99,84 \\
\hline & & Ular siput & Pareas carinatus & 5,12 \\
\hline & & Ular tikus & Ptyas korros & 17,92 \\
\hline & & Ular sapi & Rhabdophis chrysargos & 1,28 \\
\hline & & Ular bandotan tutul & Xenochrophis piscator & 1,28 \\
\hline 2 & Elapidae & Ular welang & Bungarus fasciatus & 1,28 \\
\hline 3 & Viperidae & Ular mati ekor & Trimeresurus insularis & 2,56 \\
\hline
\end{tabular}

litian yang dilakukan oleh Qurniawan et al. (2009) di kawasan wisata Gua Kiskendo ditemukan enam spesies ular. Menurut McKay (2006) di Bali ditemukan 31 spesies ular, sedangkan menurut informasi dari Pusat Penelitian Balai Konservasi Mangrove Bali ditemukan lima spesies ular di Bali. Di wilayah Kecamatan Kuta Selatan ditemukan 12 spesies ular (Herbert et al., 2012).

Desa Pering, Kecamatan Blahbatuh, Kabupaten Gianyar merupakan daerah dengan habitat yang dapat mendukung kehidupan ular. Beberapa spesies ular juga dapat membantu petani dalam hal pengendalian hama dalam bidang pertanian (Purbatrapsila, 2009). Sebaliknya, berdasarkan informasi, masyarakat Banjar Perang Sada ada yang meninggal karena gigitan ular. Oleh karena itu, peneliti tertarik eneliti keanekaragaman ular di daerah tersebut.

\section{MATERI DAN METODE}

Penelitian ini menggunakan metode jelajah yaitu dengan cara menentukan habitat yang kemungkinan sesuai untuk ular dan mengamati secara langsung keberadaannya (Asad et al, 2012). Pada penelitian ini menggunakan senter dengan cahaya berwarna putih digunakan untuk melihat ular di malam hari, hook/pengait untuk menangkap ular yang berbisa. Identifikasi dilakukan dengan mengacu kepada Cox et al. (1998), McKay (2006), dan Marlon (2014).

Pengamatan dilakukan pada malam hari dari pukul 19:00 - 23:00 WITA di Desa Pering, Kecamatan Blahbatuh, Kabupaten Gianyar, dengan pengambilan sampel dilakukan pada tanggal 28 Januari - 4 Februari 2015 dengan tiga kali pengulangan pada masing - masing plot dan difokuskan di Banjar Perang Sada pada dua plot (100 x 50) $\mathrm{m}^{2} /$ tempat yang berbeda dengan habitat sama yaitu persawahan yang ada di dekat pemukiman warga dan di dekat Pura Beji. Pengamatan dilakukan dengan menjelajahi plot yang sudah ditentukan, kemudian spesies ular yang ditemukan dicatat dan diidentifikasi in situ mengacu pada buku panduan. Ular yang telah diidentifikasi kemudian dikembalikan ke habitat aslinya.

\section{HASIL}

Jumlah spesies ular yang ditemukan selama pengamatan adalah 128 individu ular yang termasuk dalam tiga famili yaitu Coubridae, Elapidae, dan Viperidae. Ular yang ditemukan selama pengamatan beserta dengan jumlah individunya disajikan pada Tabel 1.

Berdasarkan hasil penelitian ditemukan sembilan spesies ular di Desa Pering, Kecamatan Blahbatuh, Kabupaten Gianyar, termasuk ke dalam tiga famili yaitu family Coloubridae yang terdiri dari spesies Ahaetulla prasina, Boiga cynodon, Dendrelaphis pictus, Pareas carinatus, Ptyas korros, Rhabdophis crysargos, dan Xenochrophis piscator, famili Elapidae dan Viperidae yang masing-masing terdiri dari satu spesies berturutturut Bungarus fasciatus dan Trimeresurus insularis. Seluruh spesies yang ditemukan diklasifikasikan dan dideskripsikan di bawah ini:

1. Kindom : Animalia

Phylum : Chordata

Kelas : Reptilia

Ordo : Squamata

Subordo : Serpentes

Famili : Colubridae

Genus : Ahaetulla

Spesies : A. prasina Shaw (1802)

Ahaetulla prasina atau ular pucuk merupakan ular dengan warna hijau dengan ciri khusus yaitu kepala berbentuk segitiga lancip, pupil mata melintang, berbisa lemah dan umumnya tidak berbahaya. Ular pucuk aktif pada siang hari (diurnal) memangsa katak, burung kecil, dan mamalia kecil. Habitat ular pucuk adalah semaksemak dan kebun (Marlon, 2014). Pada penelitian ini tujuh ekor ular pucuk ditemukan di plot satu dan 19 ekor di plot dua.

2. Ular kucing bergigi panjang: Boiga cynodon Boie (1827)

Ular ini berwarna cokelat dengan ciri garis hitam/ coklat tua melintang pada tubuhnya, berbisa sedang dan umumnya tidak berbahaya bagi manusia. Ular kucing bergigi panjang aktif pada malam hari (nokturnal) memangsa mamalia kecil, burung, dan telur.Habitat ular ini adalah semak - semak dan hutan (Marlon, 2014). 
Pada penelitian ini B.cynodon hanya ditemukan satu ekor di plot dua.

3. Ular Tali: Dendrelaphis pictus Gmelin (1789)

Ular tali ciri garis hitam yang membagi kedua tubunya dari kepala sampai ke ekor dengan bisa lemah dan tidak berbahaya bagi manusia. Ular ini hidup diurnal dengan memangsa kadal dan katak pohon. Daerah rawa, semak, sawah dan taman sekitar rumah merupakan habitat dari ular ini (Marlon, 2014). Pada penelitian ini D. pictus ditemukan 30 ekor di plot satu dan 48 ekor di plot dua.

4. Ular siput: Pareas carinatus Wagler (1830)

Pareas carinatus merupakan ular yang berukuran kecil dengan garis hitam terang pada tubuh dorsal semakin kebawah semakin memudar, dan ular ini tidak memiliki bisa. Ular siput adalah ular nokturnal yang memangsa bekecot dan siput yang tidak bercangkang. Habitat dari ular ini adalah semak, lingkungan perkebunan hingga dekat dengan pemukiman warga (Marlon, 2014). Pada penelitian ini $P$. carinatus ditemukan dua ekor di plot satu dan dua ekor di plot dua.

5. Ular tikus : Ptyas korros Schlegel (1837)

Ptyas korros merupakan ular yang memiliki ciri dengan mata yang besar, tubuh berwarna coklat, tubuh bagian ventral berwarna putih kekuningan dan tidak berbisa. Ular ini diurnal dan memangsa tikus, katak dan kadal. Ular ini dapat membantu dalam bidang pertanian sebagai biokontrol tikus. Ptyas korros sering ditemukan pada semak, dekat dengan air dan di perbukitan (Marlon, 2014). Pada penelitian ini P. korros ditemukan dua ekor pada plot satu dan 12 ekor pada plot dua.

6. Ular sapi: Rhabdophis chrysargos Schlegel (1837)

Rhabdophis chrysargos merupakan ular berwarna coklat dengan ciri warna merah pada kepalanya dan berbisa lemah yang tidak berbahaya. Ular ini aktif pada siang maupun malam hari (crepuscular) memangsa katak dan kodok. Habitat dari ular ini adalah daerah sepanjang sungai dan daerah berbatu yang berlubang (McKay, 2006). Pada penelitan ini $R$. chrysargos ditemukan satu ekor pada plot satu dan tidak ditemukan pada plot dua.

7. Ular bandotan tutul: Xenochrophis piscator Schneider (1799)

Xenochrophis piscator merupakan ular yang memiliki warna tubuh cokelat dengan bintik-bintik hitam disepanjang tubuhnya dan berbisa lemah. Ular ini adalah ular nokturnal yang memangsa ikan kecil dan katak. Daerah sungai, sawah tergenang, dan danau merupakan habitat dari ular ini. Pada penelitian ini $X$. piscator ditemukan satu ekor pada plot satu dan tidak ditemukan pada plot dua.

\section{Famili : Elapidae}

Genus : Bungarus

Spesies :Bungarus fasciatus Schneider (1801)

Bungarus fasciatus atau ular welang merupakan ular yang memiliki ciri tubuh berbelang kuning hitam dari tubuh dorsal hingga ventral dan memiliki bisa neurotoksin yang akan menyerang syaraf bila digigit (Lang and Vogel, 2005). Gigitannya berakibat fatal apabila tidak

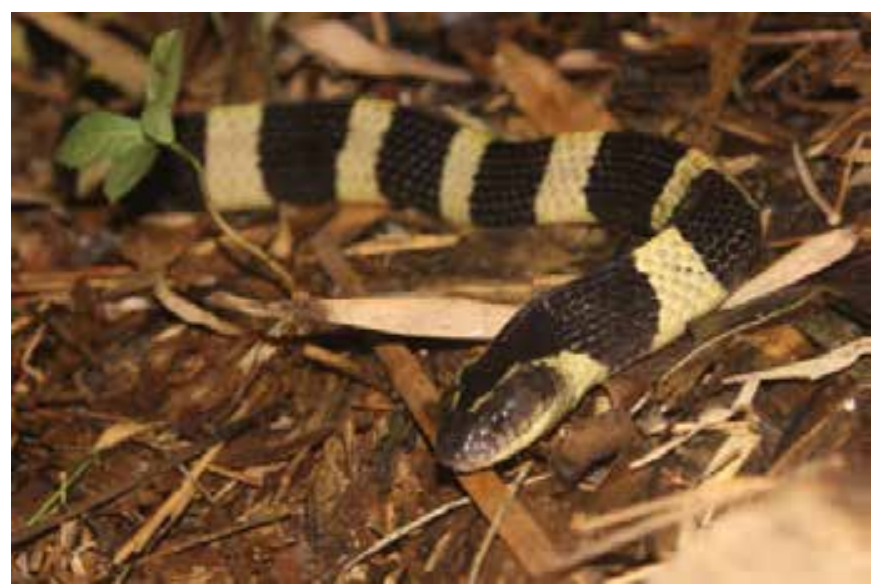

Gambar 2. Ular welang (B. fasciatus)

ditangani dengan tepat. Ular ini nokturnal, memangsa ular, kadal, katak dan hewan pengerat. Habitat dari ular ini adalah rawa-rawa, sawah, ladang, dan sering ditemukan daerah dekat air (Marlon, 2014). Pada penelitian ini B. fasciatus ditemukan satu ekor pada plot dua dan tidak ditemukan pada plot satu.

Bungarus fasciatus adalah spesies ular yang belum pernah tercatat keberadaannya di Bali. Hal ini berdasarkan pada komunikasi pribadi yang dilakukan dengan salah satu pengamat ular di Bali yaitu Nicholson (1 Februari 2015) dan juga diperkuat oleh Putra (1 Februari 2015). Penyebaran ular welang di Indonesia pernah tercatat di Pulau Jawa, Sumatra dan Kalimantan (Marlon, 2014). Selain di Indonesia, penyebaran ular welang juga ditemukan di India, Malaysia, Myanmar dan Thailand (Srinivasulu et all., 2009)

9. Famili : Viperidae

Genus : Trimeresurus

Spesies : Trimeresurus insularis Kramer (1977)

Trimeresurus insularis atau ular hijau ekor merah merupakan ular yang memiliki warna hijau dengan kepala berbentuk segitiga, ekor berwarna merah, dan memiliki bisa haemotoksin yang dapat merusak sel darah merah (Ario, 2010). Ular ini adalah ular nokturnal yang memangsa katak, tikus, kadal kecil, tokek, dan burung kecil. Habitat dari ular ini adalah semak belukar, daerah persawahan, rerumputan dan kadang berada di pohon bambu (Marlon, 2014). Pada penelitian ini T. insularis ditemukan satu ekor di masing-masing plot.

\section{PEMBAHASAN}

Persentase ular yang ditemukan di Desa Pering, Kecamatan Blahbatuh, Kabupaten Gianyar terlihat bahwa spesies yang paling banyak ditemukan adalah $D$. pictus (99,84\%). Hal ini disebabkan oleh habitat persawahan yang merupakan habitat asli dari ular ini, yang dihuni kodok, katak dan kadal (Wiguna et al., 2009). Menurut Stuebing dan Inger (1999), spesies ular ini merupakan spesies ular yang umum ditemukan pada habitat yang terganggu atau dekat dengan manusia. Faktor lain yang menyebabkan ular ini banyak ditemukan disebabkan 
karena ular ini merupakan spesies ular diurnal yang melakukan aktivitas di siang hari dan beristirahat di malam hari di atas pohon dan semak-semak, sehingga mudah teramati. Tingginya persentase ular tali yang ditemukan dalam penelitian ini juga disebabkan oleh kurangnya predator alami yang terdapat di sekitar area penelitian. Putra (2015) menyebutkan bahwa ular tali tidak dimangsa oleh ular kanibal, karena ular ini memiliki racun apabila dimangsa oleh ular kanibal

Ular dengan persentase terkecil ada empat spesies yaitu, B. cynodon, B. fasciatus, $R$. chrysargos, dan $X$. piscator (1,28\%). Hal ini kemungkinan disebabkan karena keberadaan ular ini jarang sehingga hanya ditemukan secara insidental atau tidak disengaja saat ular tersebut beraktivitas (Purbatrapsila, 2009). Boiga cynodon adalah ular arboreal yang berpindah-pindah dari satu pohon ke pohon lainnya, kurangnya pohon-pohon besar di area penelitian, memungkinkan sedikitnya jumlah ular ini yang ditemukan. Pada penelitian ini, ular B. cynodon ditemukan di semak-semak, kemungkinan ular ini sedang mencari sarang burung karena ular ini memangsa burung dan telur burung (McKay, 2006).

Bungarus fasciatus ditemukan hanya satu di plot dua, hal ini disebabkan karena ular ini hidup di dalam lubang tanah.Umumnya ular ini memanfaatkan lubang bekas sarang tikus untuk berlindung/bersembunyi (Das, 2010). Rhabdophis chrysargos dan Xenocrophis piscator adalah ular semi aquatic, yang keluar pada saat musim hujan dan menyukai area persawahanyang tergenang air (McKay, 2006). Pada penelitian ini beberapa area persawahan masih kering setelah panen padi, yang mana hal ini kemungkinan penyebab rendahnya jumlah kedua spesies ular tersebut.Xenocrophis piscator hanya ditemukan digenangan air persawahan plot satu, sedangkan $R$. chrysargos ditemukan diatas daun pepaya tepat diatas aliran sungai. Keberadaan ular ini di atas pohon yang tinggi akan memudahkan ular ini melompat ke sungai apabila merasa terganggu.

Penelitian ini menemukan dua spesies ular berbisa yaitu Bungarus fasciatus atau ular welang dan Trimeresurus insularis atau ular hijau ekor merah. Ular welang merupakan ular yang memiliki taring bisa proteroglypha, terdapat pada rahang atas bagian depan. Ukuran taring bisa tidak besar namun memiliki alur untuk menyalurkan bisa dari kantung bisa yang terdapat di bawah mata. Spesies ular pada golongan ini memakan mangsanya dengan cara menyuntikkan bisa dengan cepat dan efisien, setelah mati mangsanya ditelan secara perlahan. Bisa spesies ular ini adalah bisa yang sangat kuat yang dapat merusak syaraf (neurotoksin) dan sangat mematikan (Marlon, 2014).

Ular hijau ekor merah memiliki taring bisa Solenoglypha yang terletak pada bagian depan rahang atas dan dapat dilipat ke belakang di dalam mulut. Spesies ular pada golongan ini memakan mangsanya dengan cara menyuntikkan bisa dengan cepat dan efisien. Setelah mati, mangsa baru ditelan secara perlahan. Bisa spesies ular ini adalah bisa yang dapat merusak sel darah merah (hemotoksin), jika tidak ditangani dengan cepat dapat menyebabkan kematian (Marlon, 2014).

Masyarakat yang melakukan aktivitas pergi ke sawah pada malam hari disarankan agar menggunakan sepatu boot, membawa senter, dan apabila melihat ular disarankan agar tidak mengganggu atau membunuh ular tersebut. Ular umumnya menyerang karena mempertahankan diri dari ancaman.

\section{SIMPULAN}

Sembilan spesies ular ditemukan di Desa Pering, Kecamatan Blahbatuh, Kabupaten Gianyar yaitu, Ahaetulla prasina, Boiga cynodon, Dendrelaphis pictus, Pareas carinatus, Ptyas korros, Rhabdophis chrysargos, Xenochrophis piscator, Bungarus fasciatus, dan Trimeresurus insularis. Ular yang paling umum ditemukan adalah Dendrelaphis pictus dan ular yang memiliki bisa mematikan adalah Bungarus fasciatus, dan Trimeresurus insularis.

\section{UCAPAN TERIMAKASIH}

Terima kasih disampaikan kepada Bali Reptile Rescue yang telah membantu dalam penelitian ini. Ni Luh Watiniasih, dosen Jurusan Biologi Fakultas MIPA Universitas Udayana yang telah membantu dalam penulisan jurnal ini, dan seluruh rekan-rekan mahasiswa Jurusan Biologi Fakultas MIPA Universitas Udayana.

\section{KEPUSTAKAAN}

Ario A. 2010. Panduan Lapangan Mengenai Satwa Taman Nasional Gunung Gede Pangrango. Conservation International Indonesia, Jakarta.

Asad S, J.L. McKay and A.P. Putra. 2012. The Herpetofauna of Nusa Penida, Indonesia. Research Articles of Herpetological Bulletin. Number 122.

Cox, M. J., P.D. Peter, N. Jarujin and T. Kumthorn. 1998. A Photograhic Guide to Snakes and Other Reptiles of Peninsulr Malaysia, Singapore and Thailand. New Holland.

Das, Indraneil. 2010. A field Guide to the Reptiles of South-east Asia. New Holland Publishers (UK) Ltd.

De Rooij,N. 1917. The Reptiles Of The Indo-Australian Archipelago. Ophidia. Volume II. EJ Brill, Ltd., Lieden.

Herbert, A.L.T Rompis, I.W. Batan. 2012. Spesies Ular dan Sebarannya di Kecamatan Kuta Selatan Badung Bali. Fakultas Kedokteran Hewan Universitas Udayana.

Hodges, R. 1993. Snakes of Java with Special Reference to East Java. British Herpetology Society Bulletin 43:15-32.

Lang, D R. and G. Vogel. 2005. The Snake Of Sulawesi (A Field Guide to the Land Snakes of Sulawesi with Identification Keys). Edition Chimaera, Frankfurt am Main. Germany.

Marlon, R. 2014. Panduan Visual dan Identifikasi La- 
pangan : 107+ Ular Indonesia. Jakarta : Indonesia Printer.

McKay, J.L. 2006. Reptil dan Ampibi di Bali. Krieger Pu Com. Malabar, Florida. Hal:85-140.

Mumpuni. 2001. Keanekaragaaman Herpetofauna di Taman Nasional Gunung Halimun, Jawa Barat. Berita Biologi 5(6):711-720.

Purbatrapsila, A. 2009. Studi Keanekaragaman Spesies dan Sebaran Spasial Ular Pada Beberapa Tipe Habitat di Taman Nasional Tanjung Puting, Kalimantan Tengah. Departemen Konservasi Sumberdaya Hutan Dan Ekowisata Fakultas Kehutanan Institut Pertanian Bogor. (Skripsi). Bogor.

Putra, I. G. A. P. 2015. Spesies-spesies Ular (Serpentes) yang ditemukan Di Desa Singapadu, Kabupaten Gianyar, Bali (Tesis). Denpasar: Universitas Udayana. Bali

Qurniawan, T.F., Trijoko, R. Epilurahman. 2009. Mengungkap Keanekaragaman Herpetofauna di Kawasan Wisata Gua Kiskendo Sebagai Upaya Pelestarian Fauna Indonesia. LitBang News Edisi Januari-Maret.
Departemen Penelitian dan Pengembangan. Hal: 31-34

Sidik, I. 1998. An Inventory of Amphibians and Reptiles at Gunung Halimun National Park. Dalam: Research and Conservation of Biodiversity in Indonesia. Vol. IV: Gunung Halimun the Last Submontane Tropical Forest in Java. LIPI-JICA-PHPA, Bogor. Hal:141147.

Srinivasulu, C., D. Venkateshvarlu and M. Seetharamaraju. 2009. Rediscovery of the Banded Krait Bungarus fasciatus (Schneider 1801) (Serpentes : Elapidae) from Warangal District, Andhra Pradesh, India. Journal of Threatened Taxa. Volume : 1 No : $6 \mathrm{Hal}: 353-354$.

Stuebing, R.B., R.F. Inger. 1999. A Field Guide to the Snake of Borneo. Natural History Publication (Borneo). Kota Kinabalu.

Wiguna, C., Dharmono, Kaspul. 2009. Inventarisasi Spesies Ular di Desa Keliling Benteng Ilir Kecamatan Sungai Tabuk Kabupaten Banjar. Jurnal WahanaBio Volume I. 